\title{
Orientation in Polyalkylation of Polycyclic Aromatic Hydrocarbons. Structure Determination by NMR Spectroscopy
}

\author{
ARNE BERG, HANS JøRGEN JAKOBSEN and \\ STEFFEN RADICH JOHANSEN
}

Department of Chemistry, University of Aarhus, DK-8000 Arhus C, Denmark

\begin{abstract}
The orientation in Friedel-Crafts polyalkylation (isopropylation and tert butylation) of pyrene and phenanthrene has been studied by NMR spectroscopy. The results suggest that a severe steric effect (peri-effect) is operating in tert-butylation. $\mathrm{H}-\mathrm{H}$ as well as ${ }^{13} \mathrm{C}-\mathrm{H}$ coupling constants have been obtained from the ${ }^{13} \mathrm{C}-\mathrm{H}$ satellite spectra. Calculated spectra of two phenanthrsne derivatives are reported.
\end{abstract}

The polyalkylation of condensed aromatic systems has not been much 1 studied, due to often troublesome separative work involved and the difficulty of identification of the possible isomers. Orientation problems can, however, be successfully attacked by means of NMR spectroscopy. ${ }^{1}$ We have studied the orientation in isopropylation and tert-butylation of pyrene and in tert-butylation of phenanthrene using ${ }^{1} \mathrm{H}-\mathrm{NMR}$ techniques, including ${ }^{13} \mathrm{C}-\mathrm{H}$ satellite and double resonance experiments. Some theoretical spectra have been calculated. Our results for phenanthrene do not agree with the literature.

\section{RESULTS}

Pyrene (I) reacts with tert-butyl chloride and aluminium chloride or bromide to give a di-tert-butylpyrene. ${ }^{2,3}$ The orientation of the substituents has been unknown, although by analogy to the products from all other known electrophilic substitution reactions of pyrene ${ }^{4,5}$ the compound has been thought to be the 1,6-derivative. ${ }^{2} \mathrm{NMR}$ studies show that it is in fact 2,7-di-tert-butylpyrene (II). With tert-amyl chloride a dialkylpyrene is likewise formed, ${ }^{3}$ and in this too the substituents occupy positions 2 and 7. 


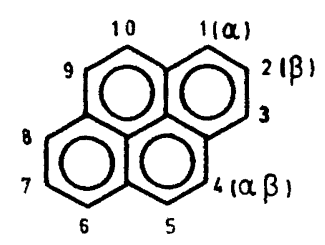

1

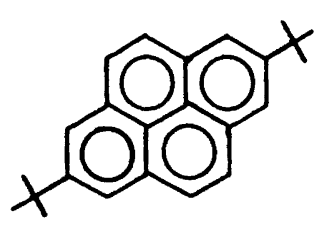

II

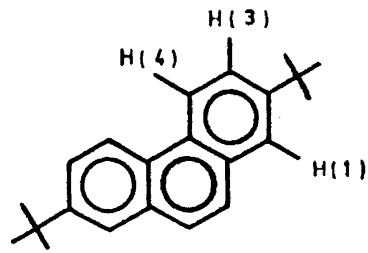

III

Secondary alkyl halides (isopropyl, cyclopentyl, cyclohexyl) easily tetraalkylate ${ }^{*}$ pyrene, $^{3}$ and we have found that the alkyl groups enter the four normal ${ }^{4}$ positions $(1,3,6$, and 8$)$.

It has been reported ${ }^{2}$ that phenanthrene reacts with tert-butyl chloride and aluminium chloride to give a di-tert-butylphenanthrene (m.p. $102^{\circ}-103^{\circ}$; picrate, m.p. $204^{\circ}$ ) that could be oxidized, with the loss of a tert-butyl group, to a compound (m.p. $186-187^{\circ}$ ) identical with the known ${ }^{6} 3$-tert-butyl-9, 10-phenanthrenequinone; this, in turn, could be reduced to the likewise known $^{6}$ 3-tert-butylphenanthrene (m.p. 53-54 ${ }^{\circ}$ ). The identifications were based on agreement in melting points. From this it was concluded that the alkylation product was 3,9-di-tert-butylphenanthrene.

In repeating these reactions we found as the only identifiable alkylation product a compound (yield $60 \%$ ) that we, by NMR spectroscopy, could show to be 2,7-di-tert-butylphenanthrene (III). The melting point of III is $159.5-160.5^{\circ}$, and the picrate derivative melts at $206-207^{\circ}$. Oxidation of III with chromic anhydride in acetic acid proceeded without loss of an alkyl group to the corresponding 9,10-quinone (IV, m.p. 145.5-146.5 ). This structure follows from the NMR spectrum and from the formation of an azine (m.p. 257.5-258.5 ) with ortho-phenylenediamine. The azine from the previously reported oxidation product had melting point $232^{\circ}$ (sintering at $\left.195^{\circ}\right) .^{2}$

\section{NMR SPECTRA}

Tetraisopropylpyrene. The NMR spectrum $\left[\mathrm{CDCl}_{3}, 6 \%(\mathrm{w} / \mathrm{v})\right]$ of this compound is consistent with the 1,3,6,8-orientation of the four isopropyl groups. The aromatic protons appear as two sharp singlets $(\delta 8.33$ and 7.97 $\mathrm{ppm}$, intensity ratio $2: 1$ ) corresponding to four $\alpha \beta$ - and two $\beta$-protons, respectively (for these symbols, ${ }^{1}$ see formula 1 ). These assignments follow from the facts that $\alpha \beta$-protons in pyrene ${ }^{7}$ have their chemical shift at slightly lower field than $\beta$-protons and that secondary as well as primary alkyl groups shift ortho-protons to higher and peri-protons to lower field. The chemical shift difference between the two groups of protons in tetraisopropylpyrene $(0.36 \mathrm{ppm})$ is therefore increased over the corresponding difference in pyrene $(0.073 \mathrm{ppm}) .{ }^{7}$ The aliphatic signals, a well resolved heptet (centered

* The fact that pentaalkylpyrenes as well as isomeric tetraalkylpyrenes can be formed ${ }^{3}$ will be considered in a subsequent paper. 
about $\left.\delta 4.09 \mathrm{ppm}, J=6.9 \mathrm{~Hz}[4 \mathrm{H}]{ }^{*}\right)$ and a doublet $(\delta 1.53 \mathrm{ppm}, J=6.9 \mathrm{~Hz}$ $\left[\begin{array}{ll}24 & \mathrm{H}\end{array}\right]$ ), show that the four isopropyl groups are equivalent, as is ebvious from the aromatic signals too. The only other orientation $(4,5,9,10)$ fulfilling this requirement should produce an aromatic $\mathrm{AB}_{2}$ spectrum.

$D i$-tert-butylpyrene. The extremely simple NMR spectrum $\left[\mathrm{CDCl}_{3}, 8 \%\right.$ $(w / v)]$ consists of only three sharp signals $(\delta 8.17,7.98$, and $1.57 \mathrm{ppm}$, intensity ratio $2: 2: 9$ ). All orientations with two equivalent substituents except the 2,7-orientation (II) should lead to spin-spin splitting, and although fortuitous magnetic equivalence between chemically different protons is possible, it does not seem very probable. Moreover, no indication of line splitting or broadening was observed when the spectrum (expanded, sweep width $50 \mathrm{~Hz}$ ) was recorded using six different solvents (Table 1), nor was any splitting observable at $100 \mathrm{Mc} / \mathrm{s}$. As the chemical shift of the $\alpha$-protons in pyrene ${ }^{7}$ falls at slightly lower field than that of the $\alpha \beta$-protons, and as it has been shown ${ }^{8}$ that the tert-butyl group (in tert-butylbenzene) causes a shift of ortho-protons to lower field, the signals at $\delta 8.17$ and $7.98 \mathrm{ppm}$ were assigned to the $\alpha$-protons and the $\alpha \beta$-protons, respectively. The chemical shift difference between $\alpha$-protons and $\alpha \beta$-protons in II (see Table 1 ) is, therefore, increased over that in pyrene $(0.10 \mathrm{ppm})^{7}$ as a result of the perturbing effect of the tert-butyl groups on the $\alpha$-protons.

Table 1. Solvent dependence of the chemical shifts (in ppm, $\delta$-units) of the aromatic protons of 2,7-di-tert-butylpyrene.

\begin{tabular}{|l|c|c|c|c|}
\hline Solvent & Conc. \%(w/v) & $\delta_{\alpha}$ & $\delta_{\alpha \beta}$ & $\delta_{\alpha}-\delta_{\alpha \beta}$ \\
\hline $\mathrm{CCl}_{4}$ & 10 & 8.09 & 7.92 & 0.17 \\
$\mathrm{CS}_{2}$ & 8 & 8.04 & 7.87 & 0.17 \\
$\mathrm{CS}_{2}$ & 18 & 8.10 & 7.92 & 0.18 \\
$\mathrm{CDCl}_{3}$ & 8 & 8.16 & 7.98 & 0.18 \\
$\mathrm{CDCl}_{3}$ & 20 & 8.17 & 7.99 & 0.18 \\
$1,4-$ Dioxan $_{\mathrm{CH}_{3} \mathrm{COCH}_{3}}$ & 9.5 & 8.19 & 8.00 & 0.19 \\
$\mathrm{C}_{6} \mathrm{D}_{6}$ & 11 & 8.29 & 8.08 & 0.21 \\
\hline
\end{tabular}

Dibromo-di-tert-butylpyrene. ${ }^{3}$ Di-tert-butylpyrene is brominated to give a dibromo derivative, which, by spectral evidence, is 1,6-dibromo-2,7-di-tert-butylpyrene. The NMR spectrum $\left(\mathrm{CS}_{2}, 1 \%(\mathrm{w} / \mathrm{v})\right)$ is very clear, showing a singlet $(\delta 8.37 \mathrm{ppm}[4 \mathrm{H}])$ and an AB-system ( $\delta 8.77$ and $8.14 \mathrm{ppm}, J=9.2$ $\left.\mathrm{Hz}\left[\begin{array}{ll}4 & H\end{array}\right]\right)$ in the aromatic part. These signals originate from the $3,8-$ and $4,5,9,10$-protons, respectively. The tert-butyl groups show up as a singlet at $\delta 1.78 \mathrm{ppm}$.

The crowding of substituents in the 1- and 2- (and 6- and 7-) positions is demonstrated by the change in chemical shift of the proton in position 10 on going from 1,6-dibromopyrene ${ }^{* *}$ to the compound in question. The

\footnotetext{
* Integrated intensity.

** The NMR spectrum of this compound $\left[\mathrm{CS}_{2}, 1 \%(\mathrm{w} / \mathrm{v})\right]$ will be published in a forthcoming paper.
} 


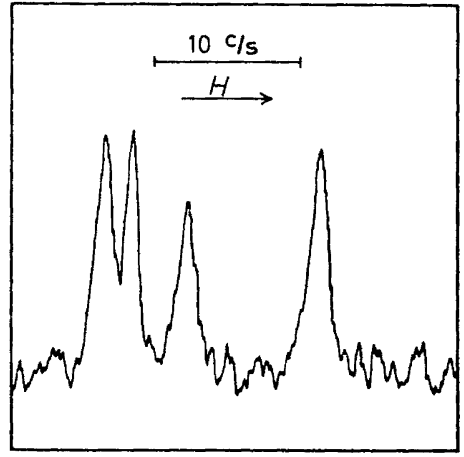

Fig. 1. ${ }^{13} \mathrm{C}-\mathrm{H}$ satellites (downfield) of 2,7-di-tert-butylpyrene.

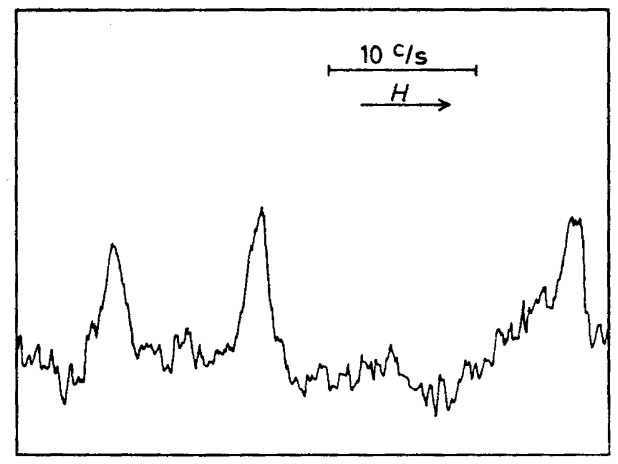

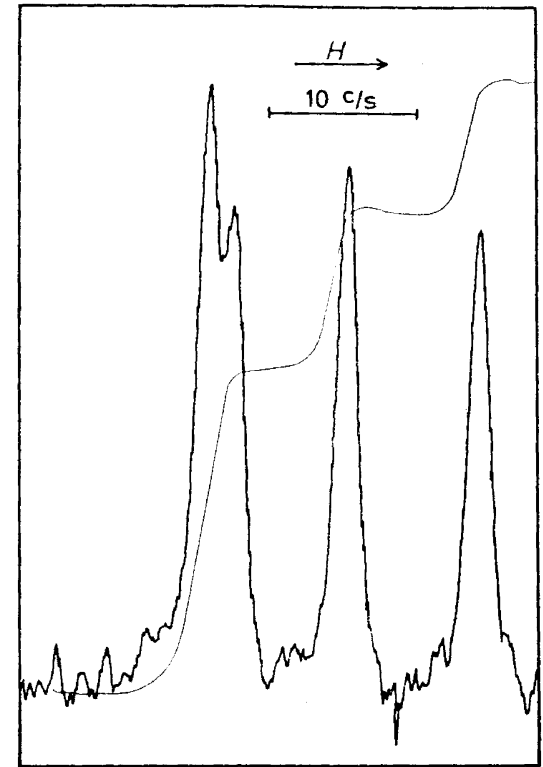

Fig. 2. ${ }^{13} \mathrm{C}-\mathrm{H}$ satellites (upfield) of 2,7di-tert-butylpyrene.

Fig. 3. ${ }^{13} \mathrm{C}-\mathrm{H}$ satellites (downfield) of 1,3,6,8-tetraisopropylpyrene.

chemical shift of the peri-perturbed $H(10)$ relative to that of $H(9)$ (unperturbed) is 0.63 and $0.32 \mathrm{ppm}$ downfield for 1,6-di-bromo-2,7-di-tertbutylpyrene and 1,6-dibromopyrene, respectively. The difference $(0.31 \mathrm{ppm})$ can be taken as a measure of the buttressing effect ${ }^{9}$ of the tert-butyl group on the bromo substituent.

The ${ }^{13} \mathrm{C}-\mathrm{H}$ satellite spectra of the aromatic parts of di-tert-butylpyrene (Figs. 1 and 2) and tetraisopropylpyrene (Fig. 3) confirm the above conclusions.

The upfield as well as the downfield satellites were recorded for di-tertbutylpyrene. Each part consists of two doublets. The coupling constants 
$(1.7 \mathrm{~Hz}$ and $8.9 \mathrm{~Hz}$ ) in these doublets are conclusive evidence of 2,7-orientation (II), one of them $(1.7 \mathrm{~Hz})$ being a typical meta-coupling constant between two $\alpha$-protons like that found for a series of 4 -substituted pyrenes. ${ }^{10}$ The other coupling constant falls outside the range $(9.3-9.5 \mathrm{~Hz})$ given by Martin et al..$^{11}$ for ortho-coupling between two $\alpha \beta$-protons. This is also true, however, of the $\alpha \beta$ - $\alpha \beta$-coupling constant found in the ${ }^{13} \mathrm{C}-\mathrm{H}$ satellite spectrum (downfield part only, a singlet and a doublet) of 1,3,6,8-tetraisopropylpyrene (Fig. 3 ), although for this compound the value $(9.8 \mathrm{~Hz})$ is higher than the range cited. This range was obtained from a study of 1-substituted pyrenes, ${ }^{11}$ and the present results consequently show that $J_{\alpha \beta-\alpha \beta}$ is subject to a greater variation depending on the number and positions of the substituents and, presumably, also on their nature.

From the ${ }^{13} \mathrm{C}-\mathrm{H}$ satellite spectra the ${ }^{13} \mathrm{C}-\mathrm{H}$ coupling constants for $\beta$-protons $(\sim 154 \mathrm{~Hz}), \alpha$-protons $(\sim 156 \mathrm{~Hz})$, and $\alpha \beta$-protons $(\sim 159 \mathrm{~Hz})$ have been estimated.

It has been shown ${ }^{12}$ that the nuclear Overhauser effect can be used as a means of making assignments in NMR spectroscopy. By irradiating the tert-butyl protons, which in II will be rather close to the $\alpha$-protons, the upfield aromatic signal was not affected, whereas the downfield signal was found to increase $(20 \%$ ) and consequently, from this evidence too, must be assigned to the $\alpha$-protons.

Di-tert-butylphenanthrene (III). The NMR spectrum (Fig. 4a), $\left[\mathrm{CS}_{2}, 20 \%\right.$ $(w / v)]$ could be analysed as an $A B X$ spectrum $(X=H(4))$ with a singlet $(H(9), H(10))$ superposed on it. Starting from this analysis, the spectrum

Fig. 4. NMR spectrum (AB-part) of 2,7di-tert-butylphenanthrene. a. Experimental spectrum. b. Calculated spectrum.

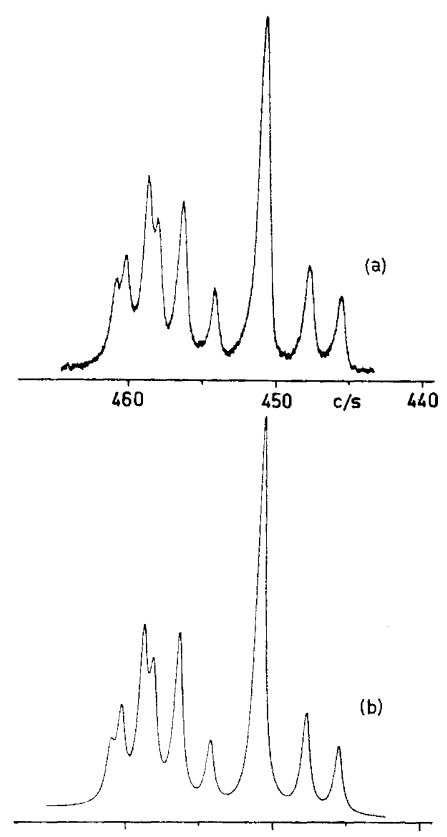

Acta Chem. Scand. 23 (1969) No. 2 

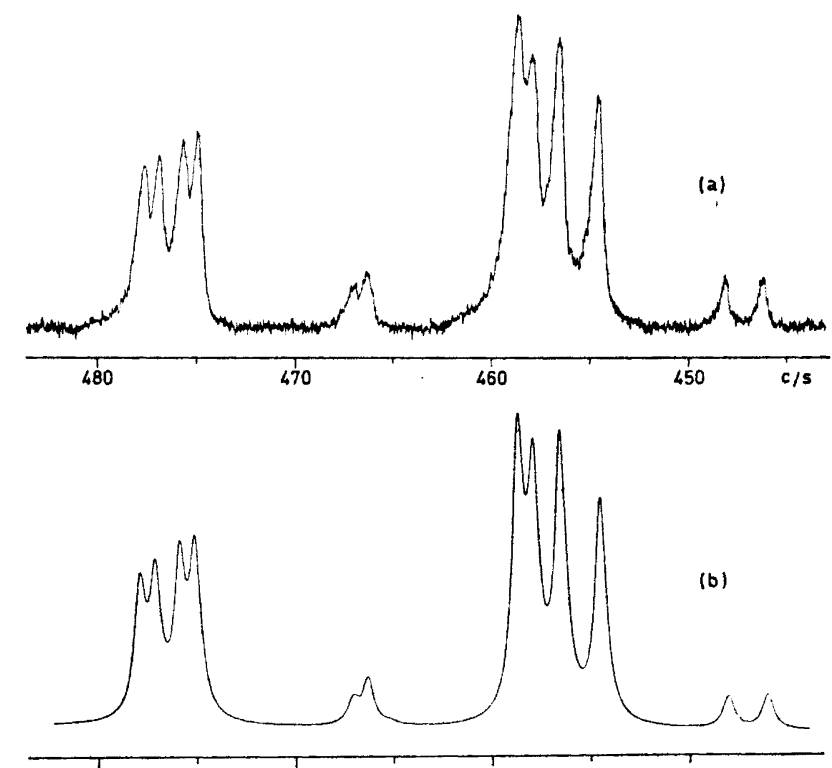

Fig. 5. NMR spectrum (AB-and X-parts) of 2,7-di-tert-butyl-9,10-phenanthrenequinone. a. Experimental spectrum. b. Calculated spectrum.

was calculated as an $\mathrm{ABC}$ spectrum and refined (Fig. 4b). The parameters used are shown in Table 2. Only the AB-part of the spectrum is shown in Fig. 4. The $\mathrm{X}$-part consists of two broad peaks.

$D i$-tert-butylphenanthrenequinone (IV). The NMR spectrum $\left(\mathrm{CS}_{2}, 20 \%(\mathrm{w} / \mathrm{v})\right)$ of this compound (Fig. 5a) was treated in the same way as described for III; here $\mathrm{X}$ is the 1-proton. The parameters for the calculated spectrum (Fig. 5b) are shown in Table 2.

Table 2. NMR parameters (calculated spectrum) of 2,7-di-tert-butylphenanthrene (III) and (III)-9,10-quinone. Chemical shifts in $\mathrm{Hz}$ at $60 \mathrm{Mc} / \mathrm{s} .{ }^{a}$ Coupling constants in $\mathrm{Hz}$.

\begin{tabular}{|c|c|c|}
\hline & III & III-9,10-quinone \\
\hline$H(1)$ & $459.2 \pm 0.5$ & $476.2 \pm 0.5$ \\
$H(3)$ & $451.5 \pm 0.5$ & $453.3 \pm 0.5$ \\
$H(4)$ & $500.5 \pm 0.5$ & $460.5 \pm 0.5$ \\
$J_{13}$ & $+2.18 \pm 0.04$ & $+2.35 \pm 0.05$ \\
$J_{14}$ & $+0.48 \pm 0.04$ & $+0.30 \pm 0.05$ \\
$J_{34}$ & $+8.80 \pm 0.05$ & $+8.40 \pm 0.05$ \\
\hline
\end{tabular}

a Chemical shifts of $H(9)$ and $H(10)$ in III: 450.8 . 
Double resonance (partial decoupling) experiments indicate that the coupling constants in both III and IV have the same sign, and as orthocoupling constants usually are positive ${ }^{13}$ all three will be positive.

\section{DISCUSSION]}

The 2,7-orientation of tertiary alkyl groups in Friedel-Crafts alkylation of pyrene is remarkable because it represents the first clearly observed deviation from the otherwise strictly followed orientation rules of pyrene. ${ }^{4}$ It appears that four isopropyl groups easily enter the 1,3,6,8-positions without any trace of a 2,7-derivative being formed. Obviously a steric factor must be operating in tert-butylation; the tert-butyl group, unlike the isopropyl group, is bulky on all sides, which makes the transition state for substitution in the normal positions less favourable. This steric factor probably involves the peri-hydrogens in positions $4,5,9$, and 10 . The possibility that the abnormal orientation is the result of a rearrangement following initial attack on the adjacent (normal) positions seems not very likely. If this rearrangement occurs, it must be extremely rapid. Even when the reaction is run under mild conditions (low temperature and short reaction time) only the 2,7product, besides unreacted pyrene, can be isolated. If the hypothetical rearrangement was not very fast, 1,6- and 1,8-di-tert-butylpyrene and even 1,3,6,8-tetra-tert-butylpyrene should be among the products, and they could hardly, even in small concentrations, escape discovery by the separative technique used (thin layer and column chromatography).

The fact that the very strict substitution scheme of pyrene is broken in the case of tert-alkylation suggests that a similar steric effect will be connected with the peri-positions in other polycyclic aromatic hydrocarbons also. This is known to be the case for naphthalene, which is alkylated by the FriedelCrafts reaction preferentially in the 2-position. ${ }^{14}$ With tert-butyl chloride and aluminium chloride only 2,6- and 2,7-di-tert-butyl naphthalene could be detected. ${ }^{15}$

We have not been able to confirm the claim of Buu-Hoï and Cagniant ${ }^{2}$ that 3,9-di-tert-butylphenanthrene, which has one of the tert-butyl groups in a peri-position, is formed in the tert-butylation of phenanthrene. That this cannot be so in the present study is seen from the oxidation of the hydrocarbon to a disubstituted 9,10-quinone, and also from the fact that the NMR spectrum must originate from a symmetrical molecule. The tertbutyl groups do not occupy the 1,8- or the 4,5-positions because in both these cases the three-spin system would involve two ortho-coupling constants instead of only one. Moreover, the 4,5-positions are strongly disfavoured on steric grounds. The X-proton can only be the "bay"-proton $(\mathrm{H}(4)),{ }^{7}$ and the fact that a typical ortho-coupling constant can be assigned to the coupling between $\mathrm{H}_{\mathrm{x}}$ and one of the other protons shows that the tert-butyl groups occupy the 2,7-positions. This being the case, $\mathrm{H}_{\mathrm{x}}$ in the quinone must be identical with $\mathrm{H}(1)$, since $\mathrm{H}_{\mathrm{x}}$ does not couple with an ortho-coupling constant to any of the other protons. The deshielding of $\mathrm{H}(1)$ is partly due to the

Acta Chem. Scand. 23 (1969) No. 2 
anisotropic effect of the ortho-carbonyl group, and this effect is particularly pronounced when the carbonyl group is part of a six-membered ring. ${ }^{16}$

A. C. Hazell and J. G. Lomborg at this institute have confirmed the structure of the 2,7-di-tert-butylpyrene by a three-dimensional $\mathrm{X}$-ray analysis. This examination will be published independently at a later time.

There has been one more reason, besides the unusual orientation of the substituents, for scrutinizing this structural problem. Studies by J. H. Eggers at this institute on molecular geometry and dichroism of compounds dissolved in stretched films had thrown some doubt on the 2,7-orientation, which was directly inferred from the NMR spectrum. Whereas experimental results (unpublished) for 2,7-di-carbethoxypyrene were in agreement with empirical structure-dichroism relations, the results for the di-tert-butylpyrene were not. The reason for this is perhaps to be sought in the shape of the tert-butyl group, which in contrast to the carbethoxy group cannot be forced to have its whole skeleton coplanar with the aromatic nucleus.

\section{EXPERIMENTAL}

The NMR spectra were recorded at $60 \mathrm{Mc} / \mathrm{s}$ on a Varian A-60 spectrometer. Temperature $35^{\circ} \pm 2^{\circ}$. The chemical shifts are downfield from TMS as internal standard. The ${ }^{13} \mathrm{C}-\mathrm{H}$ satellite spectra were obtained from saturated solutions in $\mathrm{CS}_{\mathbf{2}}$ using a Varian C-1024 Time Averaging Computer. The double resonance experiments were performed by means of a Varian V-6058 A Spin Decoupler.

The $100 \mathrm{Mc} / \mathrm{s}$ spectrum of 2,7-di-tert-butylpyrene was kindly recorded by professor

E. Clar, Glasgow, on a Varian HA 100 (frequency sweep mode; temperature $33^{\circ}$ ).

In the nuclear Overhauser experiment the solution was carefully degassed and sealed under vacuum.

1,3,6,8-Tetraisopropylpyrene and 2,7-di-tert-butylpyrene were prepared as previously described $^{3}$ and further purified by chromatography on silica impregnated with caffein. ${ }^{17}$

$2,7-D i$-tert-butylphenanthrene. The procedure of Buu-Hoï and Cagniant ${ }^{2}$ for preparing the postulated 3,9-di-tert-butylphenanthrene was closely followed. When chromatography on silica with caffein was used instead of distillation in working up the rawmaterial better yields $(60 \%)$ were obtained. In the residual oil (mainly polymerisation products arising from tert-butyl chloride) only 2,7-di-tert-butylpyrene could be detected (spectroscopical evidence). M.p. 159.5-160.5 . Picrate (from hot ethanol), m.p. $206-207^{\circ}$.

2,7-Di-tert-butyl-9,10-phenanthrenequinone. 2,7-Di-tert-butylphenanthrene $(3.0 \mathrm{~g})$ was oxidized following Buu-Hoï and Cagniant. ${ }^{2}$ The crude product $(2.0 \mathrm{~g})$ had m.p. $125-35^{\circ}$. After crystallization from methanol, sublimation in vacuo, and repeated crystallization, m.p. was 145.5-146.5 . (Found: C 82.9; $\mathrm{H}$ 7.47. Calc. for $\mathrm{C}_{22} \mathrm{H}_{24} \mathrm{O}_{2}$ : C 82.46; $\mathrm{H} \mathrm{7.55)}$.

2,7 -Di-tert-butyl-dibenzo[a,c]phenazine. The quinone $(0.3 \mathrm{~g})$, dissolved in boiling ethanol, was mixed with a hot solution of phenylenediamine $(0.1 \mathrm{~g})$. The precipitated product was recrystallized from ethanol-ethylacetate $(1: 1)$ yielding $0.21 \mathrm{~g}, \mathrm{~m} . \mathrm{p}$. $257.5-258.5^{\circ}$. (Found: $\mathrm{C} 85.68 ; \mathrm{H} 7.04 ; \mathrm{N} \mathrm{7.25}$. Calc. for $\mathrm{C}_{28} \mathrm{H}_{28} \mathrm{~N}_{2}$ : C 85.67; $\mathrm{H} 7.19$; N 7.14).

\section{REFERENCES}

1. Martin, R. H., Defay, N., Geerts-Evrard, F. and Delavarenne, S. Tetrahedron 20 (1964) 897, 1073.

2. Buu-Hoï, Ng. Ph. and Cagniant, P. Ber. 77 (1944) 121.

3. Lund, H. and Berg, A. Kgl. Danske Videnskab. Selskab, Mat.Fys. Medd. 22 (No. 15) (1946) 17; Chem. Abstr. 40 (1946) $6073^{5}$. 
4. Vollmann, H., Becker, H., Corell, M. and Streeck, H. Ann. 531 (1937) 73.

5. Clar, E. Polycyclic Hydrocarbons, Academic, London-New York 1964, Vol. 2, p. 110.

6. Fieser, L. F. and Price, C. C. J. Am. Chem. Soc. 58 (1936) 1838.

7. Jonathan, N., Gordon, S. and Dailey, B. P. J. Chem. Phys. 36 (1962) 2443.

8. Bovey, F. A., Hood, F. P., Pier, E. and Weaver, H. E. J. Am. Chem. Soc. 87 (1965) 2060 .

9. Westheimer, F. H. In Newman, Steric Effects in Organic Chemistry, Wiley, New York 1956, p. 552.

10. Johansen, S. R. and Berg, A. To be published.

11. Martin, R. H., Flammang, R. and Arbaoui, M. Bull. Soc. Chim. Belges 74 (1965) 418.

12. Anet, F. A. L. and Bourn, A. J. R. J. Am. Chem. Soc. 87 (1965) 5250.

13. Emsley, J. W., Feeney, J. and Sutcliffe, L. H. High Resolution Nuclear Magnetic Resonance Spectroscopy, Pergamon, London-New York 1966, Vol. 2, p. 682.

14. Patinkin, S. H. and Friedman, B. S. In Olah, Friedel-Crafts and Related Reactions Interscience, New York-London 1964, Vol. II, p. 69.

15. Crawford, H. M. and Glessmann, M. C. J. Am. Chem. Soc. 76 (1954) 1108.

16. Martin, R. H., Defay, N. and Geerts-Evrard, F. Tetrahedron 20 (1964) 1505.

17. Berg, A. and Lam, J. J. Chromatog. 16 (1964) 157.

Received July 1, 1968. 